Village to flat, downstream areas of Long Beleh Village. The elevation range of the surveyed areas was 12-123 $\mathrm{m}$. Despite these searches, which included the likely type locality described on herbarium specimens, we did not locate $V$. pentandra.

We believe that extensive loss of forests, to oil palm plantations and coal mining, is the most likely reason for our failure to relocate $V$. pentandra. In addition, forestry companies are extracting timber from forests along the Belayan River. With these forests greatly reduced and fragmented, the areas we surveyed are some of the last remaining forested areas along this river.

Although we recommend further surveys for $V$. pentan$d r a$, especially in upstream areas of Belayan River, in the northern Tabang Regency where forests are still in relatively good condition, we are able to update the conservation assessment of this species. Based on the findings of our survey, we reassess $V$. pentandra as Critically Endangered based on criteria A2cd; i.e. with more than $80 \%$ suspected population reduction in the last three generations $\left(\mathrm{A}_{2}\right)$ based on a decline in area of occupancy, extent of occurrence and/or habitat quality (c), and potential level of exploitation (d). The forests of Kalimantan continue to be affected by conversion and degradation, and our updated assessment of this endemic tree species is an urgent call for the conservation of this and the other species of these forests.

JEAN LINSKY (๑ orcid.org/0000-0002-3657-9283) Botanic Gardens Conservation International, Richmond, Surrey, UK E-mail jean.linsky@bgci.org

IYAN ROBIANSYAH (৫ orcid.org/0000-0002-0503-458X), EngGal Primananda and Dipta Sumeru Rinandio Research Center for Plant Conservation and Botanic Gardens, Indonesian Institute of Sciences, Bogor, Indonesia

\section{Conserving the poorly known and threatened monkey-frogs of the Brazilian Cerrado highlands}

Amphibians are the most threatened vertebrate group, with at least $32 \%$ of species categorized as threatened (The IUCN Red List of Threatened Species, v. 2020-1, iucnredlist.org). Of these, $86 \%$ are categorized using geographical distribution criteria ( $\mathrm{B}_{1}$ or $\mathrm{B}_{2}$, or $\mathrm{D}_{2}$ for Vulnerable). These are also the criteria most commonly used for Amphibia in Brazil (ICMBio, 2018, Livro Vermelho da Fauna Brasileira Ameaçada de Extinção). Therefore, adequate knowledge of geographical distributions and valid taxonomy are essential for accurate species categorization.

The genus Pithecopus (Phyllomedusidae) comprises 11 species, of which four are endemic to the highlands of the Brazilian Cerrado. They mainly occur in environments threatened by habitat loss caused by mining, silviculture, livestock, fires and unsustainable tourism (Silveira et al., 2016, Plant and
Soil, 403, 129-152). Pithecopus ayeaye is categorized on the IUCN Red List as Critically Endangered, and Pithecopus centralis, Pithecopus megacephalus and Pithecopus oreades as Data Deficient. However, on the Brazilian Red List these species are categorized as Least Concern, except for P. centralis, which is categorized as Near Threatened. Being endemic, the global and national Red List categorizations for these four species should be identical. To rectify this, and to resolve uncertainties regarding geographical distributions and species delimitations, we obtained a research grant from the Critical Ecosystem Partnership Fund, implemented by Instituto Internacional de Educação do Brasil (International Education Institute of Brazil) to (1) investigate the species' geographical distribution, through fieldwork, (2) delimit species using genomic tools, (3) refine the species' Red List assessments, (4) characterize larval ecological requirements and (5) assess the impacts of water contaminants and landscape degradation on the species.

We conducted fieldwork during October 2019-February 2020, searching for the species in locations identified through a combination of ecological niche modelling and predictive distribution mapping (Silva \& Alves-Silva, 2013, Zootaxa, 3609, 213-222). We recorded one new location for $P$. megacephalus, four for $P$. ayeaye, and 12 for $P$. oreades, and located 12 new populations that need further work for taxonomic assignment. Once this has been completed, we will be able to prioritize populations (for proposals of new private reserves), update Red List categorizations, and define priority areas for conservation. In addition to support from the Critical Ecosystem Partnership Fund and Instituto Internacional de Educação do Brasil, this project, which will finish at the end of 2021, involves a partnership between one non-governmental organization, five Brazilian universities, and several researchers, students and managers.

RAFAEL MAGALHÃES (๑ orcid.org/0000-0002-2059-1288) and H. FÁtIMA GoRGULHo (৫ orcid.org/0000-0002-9557-6808) Universidade Federal de São João del-Rei, São João del Rei, Brazil

Silvana CAMPELlo (๑ orcid.org/0000-0003-1298-6279) Instituto Araguaia de Proteção Ambiental, Caseara, Brazil

FabRícius Domingos (๑ orcid.org/0000-0003-2069-9317) Universidade Federal do Paraná, Curitiba, Brazil

IASODHARA FREIRE (๑ orcid.org/0000-0002-4816-1669), CARoline OswaLd (๑ orcid.org/0000-0001-6866-9585), Daniela SANTos (๑ orcid.org/0000-0002-3753-0801), Tiago Pezzuti (৫ orcid.org/0000-0002-1162-3954) and FabRícIo SANTOS (○ orcid.org/0000-0001-9088-1750) Universidade Federal de Minas Gerais, Belo Horizonte, Brazil 
PRISCILA LEMES (10 orcid.org/0000-0002-0918-5158) and CHRISTINE STRÜSSMANN* (10 orcid.org/0000-0001-9880-9489) Universidade Federal de Mato Grosso, Cuiabá, Brazil

MARIA COELHO (ㅇ orcid.org/0000-0002-4430-6111), GUARINO COLLI* (10 orcid.org/0000-0002-2628-5652), ANA DEL PRETTE (10 orcid.org/0000-0001-6908-5020), BEATRIZ VASCONCELOS (D orcid.org/0000-0003-0101-8969) and REUBER BRANDÃO* (ㅇo orcid.org/0000-0003-3940-2544) Universidade de Brasília, Brasília, Brazil

E-mail reuberbrandao@gmail.com

${ }^{*}$ Also at: Brazilian Red List Authority group, supported by the National Center for Reptiles and Amphibians Research and Conservation, Chico Mendes Institute for Biodiversity Conservation, Brasília, Brazil

\section{New and increasing threats may have significant impact on Jamaica's black-billed parrot Amazona agilis}

The black-billed parrot Amazona agilis, currently categorized as Vulnerable on the IUCN Red List, is endemic to Jamaica, with an estimated $95 \%$ of its population believed to reside in Cockpit Country. Cockpit Country is a dense, montane, tropical forest in the west-central uplands of the island, with high levels of endemism, and traditional and Indigenous communities living on the periphery. There have been few studies-none recent-of the distribution and abundance of the area's extant species owing to the density of the forest, its remoteness, and the largely unnavigable terrain, particularly in the forest reserve.

Recent research explored the catch yields of traditional parrot hunting in Cockpit Country (Gibson, 2020, Journal of Ethnobiology, in press). Statistics for the 2018 and 2019 hunting seasons (July-September) suggest a significant decline in the black-billed parrot population, with the total take $<5 \%$ of that of the yellow-billed parrot Amazona collaria, also endemic to Jamaica. There are, however, limitations to this study. Yellow-billed parrots were used more extensively as lures during hunts than were black-billed parrots, which could account for the differences in total takes. Large flocks of black-billed parrots have been reported by Indigenous communities in fruit trees around villages, months after the hunting season. Such spatial and temporal changes in distribution may be a response to diminishing food sources within the forest interior, where parrot hunting is traditionally practiced. Although more research is needed to determine the distribution and abundance of the black-billed parrot, a number of emerging and increasing threats could place more pressure on this species, which is a habitat specialist, than on its wider-ranging congener.
Two of the three black-billed parrots caught by hunters in 2019 appear to be hybridized with the Puerto Rican parrot Amazona vittata. The 2019 hunting season also marked the first observation by the hunters, in the 42 years since the eldest living hunter began hunting, of the Near Threatened plain pigeon Patagioenas inornata. This reinvigorates ongoing debates around the possible migration of the Puerto Rican subspecies of the plain pigeon to Jamaica, where some scholars and conservationists believe it may be being misidentified as the Jamaican subspecies. The two hybridized black-billed parrots may be emerging evidence of non-migrant species from neighbouring Caribbean islands arriving in Cockpit Country. There are plans for research to investigate this, using GPS tracking. Any increased competition from such arrivals could become an additional threat to the black-billed parrot.

Currently known threats to the black-billed parrot include nest depredation by the Jamaican boa Chilabothrus subflavus. But, as part of a community-based conservation project conducted by the authors, camera traps installed in previously unmapped areas of the forest interior have recorded feral cats, black rats and mongooses. These small mammals could also be potentially responsible for blackbilled parrot nest predation, particularly in the forest interior, where the black-billed parrot breeds.

\section{Robert Cawley, Cornell Wright, Oral White and Donnell Rowe Accompong Maroon Town, St Elizabeth, Jamaica}

LYDIA GIBSON (이 orcid.org/0000-0003-3883-8485)

Department of Anthropology, University College London, London, UK. E-mail lydia.gibson.14@ucl.ac.uk

\section{The Whitley Awards 2020}

The Whitley Fund for Nature has announced the six conservation leaders, from six different countries, receiving a 2020 Whitley Award of GBP 40,00o each in 1 year of project funding. In addition, the Whitley Gold Award of GBP 60,000 was presented to 2008 Whitley Award winner Patricia Medici of Instituto de Pesquisas Ecológicas (Institute for Ecological Research), Brazil, for her work to conserve the lowland tapir in the Atlantic Forest, Pantanal, Cerrado and Amazon biomes. In light of the COVID-19 pandemic, the Whitley Awards Ceremony, the flagship event of the UK-based charity, has been postponed until later in the year.

The 2020 Whitley Award Winners are Abdullahi Hussein Ali, Kenya (A landscape-level approach to conserve the hirola antelope); Gabriela Rezende, Brazil (Connecting populations of black lion tamarins in the Atlantic Forest); Phuntsho Thinley, Bhutan (Stepping up patrols to preserve the Endangered alpine musk deer); Jeanne Tarrant, South 